\title{
Biochemical and Hematological Alterations in Mice Inoculated with Outer Membrane Protein, Lipopolysaccharides and Whole Cells of Pasteurella multocida Type B: 2
}

\author{
${ }^{1,2}$ Faez Firdaus Jesse Abdullah, ${ }^{1}$ Lawan Adamu, \\ ${ }^{1}$ Abdinasir Yusuf Osman, ${ }^{1,2}$ Abdul Wahid Haron, ${ }^{1}$ Abdul Aziz Saharee, \\ ${ }^{3}$ Rasedee Abdullah, ${ }^{3}$ Mohd Zamri Saad and ${ }^{3}$ Zunita Zakaria \\ ${ }^{1}$ Department of Veterinary Clinical Studies, \\ ${ }^{2}$ Research Centre for Ruminant Disease, \\ ${ }^{3}$ Department of Pathology and Microbiology, \\ Faculty of Veterinary Medicine, Universiti Putra Malaysia, 43400 Serdang, Selangor, Malaysia
}

Received 2013-08-19, Revised 2013-09-11; Accepted 2013-09-17

\begin{abstract}
Haemorrhagic septicaemia in cattle and buffaloes is an economically important livestock disease in Asia including Malaysia. Therefore, the aim of this study was to investigate the biochemical and hematological alterations in mice model inoculated with outer membrane protein, lipopolysaccharides and whole cells of Pasteurella multocida type B: 2. Two hundred healthy male mice of eight to ten weeks old were used in this study. The mice were divided into four equal groups of 50 mice each. Mice of group 1 were inoculated intra-peritoneal with $1.0 \mathrm{~mL}$ sterile Phosphate Buffered Saline (PBS) pH7, group 2 were inoculated with 1.0 $\mathrm{mL}$ of $10^{9}$ colony forming unit (cfu) of P. multocida B: 2 . Mice of groups 3 and 4 were inoculated intraperitoneal with $1.0 \mathrm{~mL}$ of LPS and $1.0 \mathrm{~mL}$ of OMP, respectively. Blood samples were collected from the moribund animals and the biochemical and hematological parameters were assessed using ANOVA and Tukey-Kramer test. In the hematology, significant decreases were observed in the treatment groups compared to the control group. Increases were only observed in band neutrophils, eosinophils and plasma proteins in the treatment groups compared to the control group. In the serum biochemistry, significant increases were observed in the treatment groups compared to the control group. Decreases were only observed in AP and albumin: globulin ratio. In electrolytes, significant increases were observed in chloride and calcium in the treatment groups compared to the control. In conclusion, all the immunogen group of mice showed changes in complete blood count and biochemistry profiles with some differences between the groups.
\end{abstract}

Keywords: Biochemical, Hematological, Mice Model, Outer Membrane Protein, Lipopolysaccharides, Pasteurella Multocida type B: 2

\section{INTRODUCTION}

Haemorrhagic Septicaemia (HS) of cattle and buffaloes is a heightened and highly deadly septicaemic disease (Jesse et al., 2013a). It is caused by two unambiguous serotypes of $P$. multocida; serotype B: 2 in Asia (Jesse et al., 2013b) and E: 2 in Africa (Abubakar and Zamri-Saad, 2011). The pathogen consists of five capsular sero-groups namely $\mathrm{A}, \mathrm{B}, \mathrm{D}, \mathrm{E}$ and $\mathrm{F}$ with strong relationship between the capsular sero-group and

Corresponding Author: Faez Firdaus Jesse Abdullah, Department of Veterinary Clinical Studies, Faculty of Veterinary Medicine, Universiti Putra Malaysia, 43400 Serdang, Selangor, Malaysia 
disease proclivity (Boyce et al., 2006). At the present time, the most acceptable and extensively used serotype description system is a combination of Carter's capsulate typing and Hedleston's somatic typing. Using this method, the Asian and African haemorrhagic septicaemia serotypes are designated as B: 2 and E: 2, respectively (Ashraf et al., 2011).

Most strains of Pasteurella form a polysaccharides capsule or envelope. It is composed of polysaccharides, Lipopolysaccharides (LPS) and a variety of proteins (Ashraf et al., 2011; Jesse et al., 2013a). Both LPS and polysaccharides play imperative roles in passive haemagglutination. Jesse et al. (2013a) described the three antigen complexes from bacteria namely, alpha, beta and gamma polysaccharides protein complex, a serogroup-specific polysaccharide and LPS. The surface of Gram-negative bacteria is critical for interaction of the bacterium with the host cell environment as it mediates nutrient uptake, secretion of toxins and other products as well as avoidance of the host immune system (Jesse et al., 2013c). In mammals, including humans, activation of the innate immune system caused by infection by Gram-negative bacteria has detrimental consequences for the function of the host (Jesse et al., 2013c). The immune-mediated effects of Gram-negative bacteria are caused by the Lipid A fraction of the Lipopolysaccharides (LPS), which is also known as endotoxin. This constituent of the bacterial cell wall is constantly shed into the environment of the bacteria. In mammals, induction of an immune response by administration of LPS is commonly used to mimic a bacterial infection in a host. LPS administration in vivo increases apoptosis of the host cells reduces the ovarian steroidogenic response to gonadotropin stimulation and impairs embryonic survival (Jesse et al., 2013b).

The Outer Membrane Proteins (OMPs) of Gramnegative bacteria have a role in disease processions as they act at an interface between the host and pathogen (Ataei et al., 2009). The OMPs of P. multocida play a significant role in the pathogenesis of pasteurellosis and have been identified as potent immunogens (Abubakar and Zamri-Saad, 2011). Bacterial surface proteins have been shown to be important for conferring protective immunity in a range of infection models (Abubakar and Zamri-Saad, 2011). OMPs are the key mediators of bacterial interaction with the host environment (Jesse et al., 2013d). Recently, investigations on characterized OMPs, which include major proteins Omp A and Omp $\mathrm{H}$ and a limited number of minor OMPs, showed that these Omps are virulent factors or immunogens (Boyce et al., 2006).

Jesse et al. (2013d) has determined the differences in OMP, LPS and whole cell extracts from two vaccine strains of $P$. multocida. SDS-PAGE was used to locate the major proteins in OMP, LPS and whole cell. There were attempts of using capsules, LPS and OMP components of $P$. multocida as vaccine (Jesse et al., 2013d). Administration of LPS in fish increases the phagocytic activity of leukocytes and plasma concentration of lysozyme (Jesse et al., 2013d). LPS also acts directly on host macrophages to stimulate the expression of typical pro-inflammatory cytokines such as tumor necrosis factor and interleukins (Jesse et al., 2013d). Boyce et al. (2006) stated that LPS and OMPs can be the major protective antigens for the host. Boyce et al. (2006) had challenged mice with wild type, mutant and complemented strains of $P$. multocida B: 2 to look for crucial virulent determinant. In another study, P. multocida infection in mice was shown to resemble the infection of HS in cattle and buffaloes (Boyce et al., 2006; Jesse et al., 2013d). Clinical signs and gross pathology changes in the organs of mice after inoculation with $P$. multocida B: 2 were evident (Abubakar and Zamri-Saad, 2011).

However, there is lack of information in the response of mice towards the immunogens, particularly OMP and LPS. Furthermore, the changes in blood profiles in mice in response to these immunogens remain to be ascertained. Therefore, the aim of this study was to investigate the biochemical and hematological alterations in mice model inoculated with outer membrane protein, lipopolysaccharides and whole cells of Pasteurella multocida type B: 2 .

\section{MATERIALS AND METHODS}

\subsection{Mice}

Two hundred healthy male mice of eight to ten weeks old were used in this study. They were obtained from the Institute of Cancer Research (ICR) and kept at the Animal Resource Centre, Universiti Putra Malaysia. The animals were confirmed negative for $P$. multocida following culture of peripheral blood for bacterial isolations, housed in plastic cages and provided with water and pellet ad libitum. Ten mice were kept in each plastic cage. The mice were observed for 2 weeks prior to the experiment to make sure that they were healthy. 


\subsection{Inoculums}

Throughout the experiments, three types of inoculums were used.

\subsection{Wild-Type P. Multocida B: 2}

The wild-type $P$. multocida B: 2 used in this study was obtained from stock culture. It was isolated from a previous outbreak of HS in the state of Kelantan, Malaysia. Identification of P. multocida was made using the Gram-staining method and biochemical characterization of oxidase, urea broth, Sulphur Indole Motility (SIM), Triple Sugar Iron (TSI) and citrate tests. The isolate was confirmed to be type B: 2 by the Veterinary Research Institute (VRI) Ipoh, Perak. Pure stock culture that was stored on nutrient agar slants was sub-cultured onto $5 \%$ horse blood agar and incubated at $37^{\circ} \mathrm{C}$ for $18 \mathrm{~h}$. A single colony of P. multocida was selected and grown in Brain Heart Infusion broth (BHI), incubated in shaker incubator at $37^{\circ} \mathrm{C}$ for $24 \mathrm{~h}$ before the concentration was determined by McFarland Nephelometer Barium Sulfate Standards.

\subsection{The Lipopolysaccharide \\ (LPS) $P$.} Multocida B: 2

The LPS Extraction Kit (Intron Biotechnology) was used to prepare the inoculums of LPS. For mice experiment, LPS was extracted from $10^{9} \mathrm{cfu}$ of organisms while $10^{12} \mathrm{cfu}$ for cattle. The whole cells were centrifuged for approximately 30 seconds at $13,000 \mathrm{rpm}$ at room temperature. Then the supernatant was removed before $1 \mathrm{~mL}$ of lysis buffer was added and vortexed vigorously to lyse the bacterial cells. This was followed by adding $200 \mu \mathrm{L}$ of chloroform and vortexed vigorously. The mixture was incubated for 5 $\mathrm{min}$ at room temperature before centrifuged at 13,000 $\mathrm{rpm}$ for $10 \mathrm{~min}$ at $4^{\circ} \mathrm{C}$. Then, $400 \mu \mathrm{L}$ of the supernatant was transferred into a new $1.5 \mathrm{~mL}$ centrifuge tube and $800 \mu \mathrm{L}$ of purification buffer was added. The mixture was incubated for $10 \mathrm{~min}$ at $-20^{\circ} \mathrm{C}$. This was followed by another centrifugation at 13,000 $\mathrm{rpm}$ for $15 \mathrm{~min}$ at $4^{\circ} \mathrm{C}$. Lastly, the LPS pellet was washed with $1 \mathrm{~mL}$ of $70 \%$ ethanol and dried completely. Following that, $70 \mu \mathrm{L}$ of $10 \mathrm{mM}$ Tris-HCl $\left(\mathrm{pH}\right.$ 8.0) (Sigma $\left.{ }^{\circledR}\right)$ was added into the LPS pellet and was dissolved by boiling for $1 \mathrm{~min}$. The LPS extraction obtained was subjected to SDS-PAGE to confirm that no protein was present in the extracted LPS.

\subsection{The Outer Membrane Proteins (OMP) of $P$. Multocida B: 2}

The Qproteome ${ }^{\mathrm{TM}}$ Bacterial Protein Extraction kit was used to prepare the inoculums of OMP. For mice experiment, the OMP extracted from $10^{9} \mathrm{cfu}$ of the organism while OPM was extracted from $10^{12} \mathrm{cfu}$ for the cattle experiment. Firstly, freshly harvested cell pellets were frozen using liquid nitrogen for $24 \mathrm{~h}$ prior to the extraction. The cell pellets were then thawed for $15 \mathrm{~min}$ on ice and were re-suspended in $10 \mathrm{~mL}$ of native lysis buffer. Then the cells were incubated on ice for $30 \mathrm{~min}$ followed by centrifugation at $14,000 \mathrm{rpm}$ for $30 \mathrm{~min}$ at $4^{\circ} \mathrm{C}$. Lastly, the supernatant containing the soluble fraction of the bacterial outer membrane proteins was retained and subjected to SDS-PAGE to locate the range of protein bands present in the extraction.

\subsection{Experimental Design in Mouse Model}

The two hundred mice were divided into four equal groups of 50 mice each. Mice of group 1 were inoculated intra-peritoneal with $1.0 \mathrm{~mL}$ sterile Phosphate Buffered Saline (PBS) pH7, group 2 were inoculated with $1.0 \mathrm{~mL}$ of $10^{9}$ colony forming unit (cfu) of P. multocida B: 2 . Mice of groups 3 and 4 were inoculated intra-peritoneal with 1.0 $\mathrm{mL}$ of LPS and $1.0 \mathrm{~mL}$ of OMP, respectively. Blood samples were collected into plain blood tubes, EDTAcontaining tubes and sodium citrate containing tubes from the moribund animals. Surviving mice after $48 \mathrm{~h}$ were killed by cervical dislocation. The biochemical and hematological parameters were analyzed using ANOVA with JMP9 SAS.

\section{RESULTS}

\subsection{Blood Analysis and Biochemistry}

Prothrombin Time (PT), Partial Thromboplastin Time (PTT) and thrombocytes showed no significant difference $(p>0.05)$ between all groups (Table 1).

The leukocytes counts showed no significant $(\mathrm{p}>0.05)$ differences between groups 2 $\left(9.04 \pm 2.42 \times 10^{9} / \mathrm{L}\right)$ and $3\left(5.10 \pm 2.67 \times 10^{9} / \mathrm{L}\right)$ when compared with the control group $1\left(7.72 \pm 2.87 \times 10^{9} / \mathrm{L}\right)$, while group $4\left(2.98 \pm 0.83 \times 10^{9} / \mathrm{L}\right)$ showed significant $(\mathrm{p}=$ $0.016) 2.6$ times decreased in value (Table 1).

The lymphocyte counts showed no significant $(\mathrm{p}>0.05)$ difference between group $2\left(5.48 \pm 1.92 \times 10^{9} / \mathrm{L}\right)$ and control group $1\left(5.58 \pm 2.03 \times 10^{9} / \mathrm{L}\right)$, while group 4 $\left(0.83 \pm 0.19 \times 10^{9} / \mathrm{L}\right)$ showed a significant $(\mathrm{p}=0.016) 6.7$ times decreased in lymphocyte counts. Group 3 
$\left(2.67 \pm 1.70 \times 10^{9} / \mathrm{L}\right)$ showed a significant $(\mathrm{P}=0.022) 2$ times decreased in lymphocyte counts (Table 1).

There was no significant difference $(\mathrm{p}>0.05)$ between groups $2\left(0.49 \pm 0.07 \times 10^{9} / \mathrm{L}\right)$ and $1\left(0.50 \pm 0.15 \times 10^{9} / \mathrm{L}\right)$ in Monocyte (MO) counts whereas group 4 $\left(0.18 \pm 0.05 \times 10^{9} / \mathrm{L}\right)$ showed a significant $(\mathrm{p}=0.04) 2.7$ times decreased in monocyte counts. Group 3 $\left(0.26 \pm 0.20 \times 10^{9} / \mathrm{L}\right)$ showed a significant $(\mathrm{p}=0.049) 2$ times decreased in monocyte counts (Table 1).

There was no significant difference $(\mathrm{p}>0.05)$ between mice in groups $2\left(0.81 \pm 0.66 \times 10^{9} / \mathrm{L}\right)$ and 3 $\left(0.37 \pm 0.47 \times 10^{9} / \mathrm{L}\right)$ in Eosinophil Count (EO) when compared with control group $1\left(0.31 \pm 0.19 \times 10^{9} / \mathrm{L}\right)$. Group $4\left(0.06 \pm 0.02 \times 10^{9} / \mathrm{L}\right)$ showed a significant $(\mathrm{P}=$ $0.041) 6$ times decreased. Group $2\left(8.50 \pm 0.88 \times 10^{12} / \mathrm{L}\right)$ showed a significant decrease in erythrocytes $(\mathrm{P}=0.027)$ 1.1 times, group 3 showed $\left(8.12 \pm 0.55 \times 10^{12} / \mathrm{L}\right)$ a significant decrease $(\mathrm{P}=0.001) 1.3$ times and group 4 showed $\left(8.49 \pm 0.41 \times 10^{12} / \mathrm{L}\right)$ a significant decrease in erythrocyte counts $(\mathrm{p}=0.001) 1.3$ times (Table $\mathbf{1})$.
There was no significant $(\mathrm{p}>0.05)$ difference in plasma protein levels between mice in groups $3(60.03 \pm 24.09 \mathrm{~g}$ $\left.\mathrm{L}^{-1}\right)$ and $1\left(46.50 \pm 9.71 \mathrm{~g} \mathrm{~L}^{-1}\right)$, while mice in group 2 $\left(70.08 \pm 6.57 \mathrm{~g} \mathrm{~L}^{-1}\right)$ showed a significant increase $(\mathrm{p}=$ $0.016) 1.2$ times. Group $4\left(65.89 \pm 5.66 \mathrm{~g} \mathrm{~L}^{-1}\right)$ also showed a significant increase in the concentration of plasma protein $(\mathrm{p}=0.007) 1$ time (Table 2).

As for albumin: globulin (A: $G$ ) ratio, group 2 mice $(1.18 \pm 0.11)$ showed a significant decrease $(\mathrm{P}=0.02) 1.4$ times, group $3(0.93 \pm 0.19)$ showed a significant decrease $(\mathrm{p}=0.000) 1.7$ times and group $4(0.97 \pm 0.17)$ showed a significant decrease $(\mathrm{p}=0.002) 1.2$ times compared to control group $1(1.60 \pm 0.29)$. However, all groups did not show significant differences $(p>0.05)$ in the levels of ALT and AST (Table 2). Nevertheless, only group 4 $(1298 \pm 127.17 \mathrm{U} / \mathrm{L})$ showed significant $(\mathrm{p}<0.01)$ difference in the level of Creatinine Kinase (CK) when compared to control group $1(531.20 \pm 143.02 \mathrm{U} / \mathrm{L})$. Groups $2(511.40+126.88 \mathrm{U} / \mathrm{L})$ and $3(561 \pm 166.59 \mathrm{U} / \mathrm{L})$ did not show significant $(\mathrm{p}>0.05)$ differences.

Table 1. Blood haematology changes in mice $24 \mathrm{~h}$ post-inoculation with different immunogens of $P$. multocida $\mathrm{B}: 2$

\begin{tabular}{lcccc}
\hline Parameters & Group 1(Control) & Group 2 (P. multocida) & Group 3 (LPS) & Group 4 (OMP) \\
\hline RBC $\left(\times 10^{12} / \mathrm{L}\right)$ & $9.74 \pm 0.52$ & $* 8.51 \pm 0.88$ & $* 8.19 \pm 0.55$ & $* 8.49 \pm 0.41$ \\
Hemoglobin $(\mathrm{g} / \mathrm{L})$ & $155.60 \pm 5.68$ & $* 132.40 \pm 12.01$ & $* 130.29 \pm 10.26$ & $150.75 \pm 4.03$ \\
PCV $(\mathrm{L} / \mathrm{L})$ & $0.46 \pm 0.01$ & $* 0.40 \pm 0.03$ & $* 0.39 \pm 0.03$ & $0.46 \pm 0.006$ \\
WBC $\left(\times 10^{9} / \mathrm{L}\right)$ & $7.72 \pm 2.87$ & $9.04 \pm 2.42$ & $5.10 \pm 2.67$ & $* 2.98 \pm 0.83$ \\
Band Neutrophil $\left(\times 10^{9} / \mathrm{L}\right)$ & $0.18 \pm 0.17$ & $* 0.53 \pm 0.15$ & $0.15 \pm 0.09$ & $0.05 \pm 0.03$ \\
Seg Neutrophils $\left(\times 10^{9} / \mathrm{L}\right)$ & $1.15 \pm 0.69$ & $1.72 \pm 0.76$ & $1.53 \pm 1.17$ & $1.80 \pm 0.78$ \\
Lymphocytes $\left(\times 10^{9} / \mathrm{L}\right)$ & $5.58 \pm 2.03$ & $5.48 \pm 1.92$ & $* 2.67 \pm 1.70$ & $* 0.83 \pm 0.19$ \\
Monocytes $(\times 10 / \mathrm{L})$ & $0.50 \pm 0.15$ & $0.49 \pm 0.07$ & $* 0.26 \pm 0.20$ & $* 0.18 \pm 0.05$ \\
Eosinophils $\left(\mathrm{x} 10^{9} / \mathrm{L}\right)$ & $0.31 \pm 0.19$ & $* 0.81 \pm 0.66$ & $* 0.37 \pm 0.47$ & $0.06 \pm 0.02$ \\
Plasma Protein $(\mathrm{g} / \mathrm{L})$ & $62.80 \pm 3.42$ & $* 70.80 \pm 4.82$ & $25.17 \pm 9.90$ & $68.75 \pm 5.38$ \\
PT (seconds) & $50.40 \pm 41.80$ & $* 70.80 \pm 4.82$ & $34.26 \pm 21.18$ \\
APTT (seconds) & $169.60 \pm 86.79$ & $104.06 \pm 55.33$ & $152.57 \pm 87.99$ & $116.22 \pm 45.46$ \\
Thrombocytes $\left(\mathrm{x} 10^{9} / \mathrm{L}\right)$ & $588.60 \pm 167.03$ & $794.00 \pm 202.03$ & $524.29 \pm 243.45$ & $471.00 \pm 103.12$ \\
\hline
\end{tabular}

*Significant value $\mathrm{p}<0.05$. Comparison between immunogens groups and negative control group

Table 2. Blood serum biochemistry changes in mice at $24 \mathrm{~h}$ post-inoculation with different immunogens of $P$. multocida $\mathrm{B}: 2$

\begin{tabular}{lcccc}
\hline Parameters & Group 1(Control) & Group 2 (P. multocida) & Group 3 (LPS) & Group 4 (OMP) \\
\hline ALT (U/L) & $127.16 \pm 99.39$ & $66.32 \pm 43.03$ & $97.66 \pm 122.09$ & $162.19 \pm 241.89$ \\
AP (U/L) & $130.40 \pm 94.98$ & $172.00 \pm 71.12$ & $* 54.56 \pm 36.32$ & $65.40 \pm 30.17$ \\
AST(U/L) & $392.04 \pm 313.63$ & $144.98 \pm 97.61$ & $344.40 \pm 350.71$ & $452.63 \pm 271.38$ \\
CK (U/L) & $531.20 \pm 143.02$ & $151.40 \pm 62.69$ & $501.00 \pm 566.59$ & $* 1298.25 \pm 1266.17$ \\
Total protein (g/L) & $46.50 \pm 9.71$ & $* 70.08 \pm 6.57$ & $60.03 \pm 24.09$ & $* 65.89 \pm 5.66$ \\
Globulin (g/L) & $18.40 \pm 6.15$ & $* 32.22 \pm 3.68$ & $31.21 \pm 12.37$ & $* 33.73 \pm 4.45$ \\
A: G Ratio (unit) & $1.60 \pm 0.29$ & $* 1.18 \pm 0.11$ & $* 0.93 \pm 0.19$ & $* 0.99 \pm 0.17$ \\
Na (mmol/L) & $152.20 \pm 13.60$ & $144.74 \pm 1.97$ & $125.87 \pm 38.27$ & $150.87 \pm 2.88$ \\
K (mmol/L) & $9.96 \pm 8.41$ & $7.30 \pm 0.30$ & $6.35 \pm 3.04$ & $8.13 \pm 3.51$ \\
$\mathrm{Cl}(\mathrm{mmol} / \mathrm{L})$ & $85.48 \pm 14.67$ & $* 110.52 \pm 1.38$ & $89.78 \pm 32.68$ & $* 108.17 \pm 3.31$ \\
$\mathrm{Ca}^{2+}(\mathrm{mmol} / \mathrm{L})$ & $1.60 \pm 0.19$ & $* 2.94 \pm 0.11$ & $* 2.46 \pm 0.33$ & $* 2.39 \pm 0.12$ \\
\hline
\end{tabular}

*Significant value $\mathrm{p}<0.05$. Comparison between immunogens groups and negative control group 
Similarly, all groups did not show significant $(\mathrm{p}>0.05)$ differences in the levels of sodium ion $(\mathrm{Na})$ and potassium ion $(\mathrm{K})$. However, for Chloride Ion $(\mathrm{Cl})$, only group 3 $(89.78 \pm 32.68 \mathrm{mmol} / \mathrm{L})$ mice did not show significant $(\mathrm{p}>0.05)$ difference when compared with control group 1 (85.48+14.67 mmoL L $\left.{ }^{-1}\right)$. Groups $2(110.52+1.38 \mathrm{mmoL}$ $\left.\mathrm{L}^{-1}\right)$ and $4\left(108.17 \pm 3.31 \mathrm{mmoL} \mathrm{L}^{-1}\right)$ showed significant $(\mathrm{P}$ $=0.005) 1.4$ times and $(\mathrm{P}=0.025) 1.4$ times increased in the concentration of $\mathrm{Cl}$ ion, respectively (Table 2 ).

Group $2(2.94 \pm 0.12 \mathrm{mmol} / \mathrm{L})$ showed a significant $(\mathrm{p}$ $=0.000) 1.9$ times increased in the concentration of calcium (Ca) ion, group $3\left(2.46 \pm 0.33 \mathrm{mmoL} \mathrm{L}{ }^{-1}\right)$ a significant $(\mathrm{p}=0.000) 1.6$ times increased while group 4 $\left(2.39 \pm 0.13 \mathrm{mmoL} \mathrm{L}{ }^{-1}\right)$ a significant $(p=0.000) 1.5$ times increased when compared with control group 1 $\left(1.60 \pm 0.19 \mathrm{mmoL} \mathrm{L}^{-1}\right)$ mice (Table 2).

\section{DISCUSSION}

Mice are exquisitely susceptible to $P$. multocida (Jesse et al., 2013b) also made a similar observation using P. multocida Balb c mice while Jesse et al. (2013c) concluded that as few as two organisms could produce $100 \%$ mortality in mice. According to Abubakar and Zamri-Saad (2011), clinical disease occurred with. Pasteurella multocida infection and was found to be pathogenic for mice and could cause death after infection. Similar observation was made by Jesse et al. (2013b; 2013d), where P. multocida produced fatal infections in mice and cattle in $24 \mathrm{~h}$. The findings in this study for infected group 2 are in agreement with the others when mice died in less than $8 \mathrm{~h}$.

Hematological changes caused by bacterial infections are first detected during routine blood count. However, an animal's defensive mechanisms can react quite differently to different bacteria; therefore, there is no singular pattern in complete blood count that indicates a bacterial infection. Nevertheless, there are few abnormalities that are suggestive of bacterial infection such as neutrophilia with a left shift being the hallmark of acute inflammation (Walton, 2013; Guess et al., 2013). The Partial Thromboplastin Time (PTT) or activated Partial Thromboplastin Time (APTT) is a performance indicator measuring the efficacy of both the 'intrinsic' and the common coagulation pathways (Park et al., 2009). The Prothrombin Time (PT) measures the extrinsic coagulation pathway. They are used to determine the clotting tendency of blood, measuring warfarin dosage, liver damage and vitamin $\mathrm{K}$ status and also measures factors I, II, V, VI and X (Park et al., 2009). In this study, there is no effect towards clotting factors where the Prothrombin Time (PT), partial thromboplastin time (PTT) and thrombocytes showed no significant changes in all treated groups, therefore, the immunogens from P. multocida B: 2 did not affect the blood clotting factors and pathways.

Results of this study revealed significant reduction in the red blood cell counts in all treated groups. This is consistent with findings by Praveena et al. (2010) who concluded that inflammation is able to reduce red blood cell count. As part of the bacteriostatic mechanisms, inflammatory mediators such as tumor necrosis factor up-regulate ferritin and transfer macrophage receptors and thus, promote iron storage in the mononuclear phagocytic system. The shifting of iron to storage plus the use of iron by bacteria makes iron less available as erythroid precursors thus, leading to anaemia (Praveena et al., 2010).

Neutrophilic leukocytes are critical component of the host system, forming the first line of cellular defense against invading organisms. Neutrophils normally are released from bone marrow as mature cells, which after a brief period in circulation transmigrate through the vascular endothelium into tissues. Their primary function is ingestion and killing of bacteria (Walton, 2013; Guess et al., 2013). To perform its functions, neutrophils employ mediators that promote inflammation and eliminate invading microorganisms. In the event that the acute insult cannot be resolved, neutrophils subsequently contribute to host tissue damage, by production or release of these same mediators in certain subacute and chronic inflammatory states (Praveena et al., 2010). Mounting evidences indicate that neutrophils are not only end-stage effectors of the inflammatory response, but also modulate the immune response (Praveena et al., 2010). Increased peripheral blood neutrophil counts or neutrophilia reflects physiological, pathological or xenobiotic induced states.

Inflammation occurs in response to mediators related to infectious agents or to products of tissue injury or necrosis. Localized purulent diseases such as pyometra, empyema or abscessation stimulate greater neutrophilic responses than generalized infections or septicemias. Both total blood and circulating neutrophil pools are increased. Neutrophilia with a left shift is the classic response to inflammation, usually accompanied by lymphopenia and eosinopenia, reflecting endogenous steroids release. Monocytosis is an inconsistent finding and may reflect a response to endogenous steroids or effects of mediators of inflammation (Walton, 2013; Guess et al., 2013). In this study, inoculation of whole cells resulted in significant increased $(p<0.05)$ in neutrophil counts, which is consistent with observations by other workers (Walton, 2013; Guess et al., 2013; Praveena et al., 2010). The increased neutrophils count in this study, however, was not very high since HS is a systemic disease (Jesse et al., 2013d). 
In infectious diseases, lymphocytosis typically reflects a generalized state of lymphoid hyperplasia as a result of persistence of infectious process for weeks to months. Therefore, lymphocytosis is associated with chronic infections (Praveena et al., 2010). However, immune stimulation is also associated with lymphocytosis (Praveena et al., 2010). Therefore, the lymphocytosis observed following inoculation with OMP in this study was likely a result of immune stimulation, especially when Jesse et al. (2013a) found that OMP is important antigen of $P$. multocida $\mathrm{B}$ and $\mathrm{E}$.

Braun et al. (2010) found decreased in total serum protein, albumin and increased globulin in cases of pasteurellosis. In this study, both whole cells and OMP produced significant $(\mathrm{p}<0.05)$ increased in globulin, which may be due to the stimulation of the immune system or induction against infection (Braun et al., 2010). However, the results of total protein were not in agreement with that of Braun et al. (2010).

Chloride level was found to increase significantly $(p<0.05)$ following whole cell and OMP inoculations, suggesting acidosis. The calcium levels were significantly increased $(p<0.05)$ in all treated groups due to dehydration. Similarly, Creatinine Kinase (CK) was increased in OMP group suggesting muscular damage (Braun et al., 2010).

\section{CONCLUSION}

In conclusion, all the immunogen group of mice showed changes in complete blood count and biochemistry profiles with some differences between the groups.

\section{ACKNOWLEDGEMENT}

We thank the staff of the Department of Veterinary Clinical Studies, Universiti Putra Malaysia and Research Centre for Ruminants Disease, in particular Yap Keng Chee, Mohd Jefri Norsidin and Mohd Fahmi Mashuri, for their assistance. The project was funded by Ministry of Higher Education, Malaysia.

\section{REFERENCES}

Abubakar, M.S. and M. Zamri-Saad, 2011. Clinicopathological changes in buffalo calves following oral exposure to Pasteurella multocida $\mathrm{B}: 2$. Basic Appl. Pathol., 4: 130-135. DOI: 10.1111/j.17559294.2011.01113.x

Ashraf, A.H., S. Tariq, S.S. Nadeem and I. Manzoor, 2011. Characterization of Pasteurella multocida strains isolated from cattle and buffaloes in Karachi, Pakistan. Afr. J. Micrabiol. Res., 5: 4673-4677.
Ataei, S.R., J.C. Burchmore, A. Hodgson, R. Finucane and J.G. Coate, 2009. ldentification of immunogenic proteins associated with protection against haemorrhagic septicaemia after vaccination of calves with a live-attenuated araA derivative of Pasteurella multocida B: 2. Res. Vet. Sei., 87: $207-$ 210. DOI: $10.1016 /$ j.rvsc.2009.01.007

Boyce, J., P. Cullen, V. Nguyen, I. Wilkie and B. Adler, 2006. Analysis of the Pasteurella multocida outer membrane sub-proteome and its response to the in vivo environment of the natural host. Proteomics, 6 : 870-880. DOI: $10.1002 /$ pmic. 200401342

Braun, J.P., C. Trumel and P. Bezille, 2010. Clinical biochemistry in sheep: A selected review. Small Ruminant Res., 92: 10-18. DOI: 10.1016/j.smallrumres.2010.04.002

Guess, T.A., A. Gaggar and M.T. Hardison, 2013. New Frontiers in the Diagnosis and Treatment of Chronic Neutrophilic Lung Diseases. University of Alabama at Birmingham Medical School.

Jesse, F.F.A., L. Adamu, Y.O. Abdinasir, Z. Zakaria and R. Abdullah et al., 2013a. Clinico-pathological responses of calves associated with infection of Pasteurella multocida type B and the bacterial lipopolysaccharide and outer membrane protein immunogens. Int. J. Anim. Vet. Adv., 5: 190-198.

Jesse, F.F.A., L. Adamu, Y.O. Abdinasir, Z. Zakaria and R. Abdullah et al., 2013c. Acute phase protein profiles and clinico-pathological changes in mice associated with the infection of Pasteurella multocida type $\mathrm{B}$ and the bacterial lipopolysaccharide and outer membrane protein immunogens. J. Anim. Vet. Adv., 12: 186-193.

Jesse, F.F.A., Y.O. Abdinasir, L. Adamu, M.Y. Syamil and A.R. Omar et al., 2013b. Polymerase Chain reaction detection of pasteurella multocida type B: 2 in Mice Following Oral Inoculation. Asian J. Anim. Vet. Adv., 8: 493-501. DOI: 10.3923/ajava.2013.493.501

Jesse, F.F.A., Y.O. Abdinasir, L. Adamu, Z. Zakaria and R. Abdullah et al., 2013d. Acute phase protein profile in calves following infection with whole cell, lipopolysaccharide and outer protein extracted from Pasteurella multocida type B: 2 Asian J. Anim. Vet. Adv., 8: 655-662. DOI: 10.3923/ajava.2013.655.662

Park, M.S., W.Z. Martini, M.A. Dubick, J. Salinas, S. Butenas et al., 2009. Thromboelastography as a better indicator of hypercoagulable state after injury than prothrombin time or activated partial thromboplastin time. J. Trauma, 67: 266-275. PMID: 19667878 
Faez Firdaus Jesse Abdullah et al. / American Journal of Animal and Veterinary Sciences 8 (3): 152-158, 2013

Praveena, P.E., S. Periasamy, A.A. Kumar and N. Singh, 2010. Cytokine profiles, apoptosis and pathology of experimental Pasteurella multocida serotype A1 infection in mice. Res. Vet. Sci., 89: 332-339. PMID: 20447665
Walton, R.M. 2013. Equine Hematology. Equine Clinical Pathology. 